Zeszyty Naukowe Szkoły Głównej Gospodarstwa Wiejskiego w Warszawie Problemy Rolnictwa Światowego tom 17 (XXXII), zeszyt 3, 2017: 279-285

DOI: $10.22630 /$ PRS.2017.17.3.73

Agnieszka Tłuczak ${ }^{1}$

Uniwersytet Opolski

\title{
Konkurencyjność przestrzenna rolnictwa w krajach Unii Europejskiej
}

\section{Spatial Competitiveness of Agriculture in European Union Countries}

\begin{abstract}
Synopsis. Celem opracowania jest zbadanie relacji między poziomem konkurencyjności rolnictwa w poszczególnych krajach Unii Europejskiej a przeciętną wielkością produkcji rolnej z 1 ha użytków rolnych. Dodatkowo w pracy podjęto próbę określenia charakteru przestrzennych zmian wielkości produkcji rolnej $\mathrm{w}$ podziale na sektory. Wyniki opracowano na podstawie metody zmian konkurencyjności Estebana-Marquillasa, która pozwala na diagnostykę potencjału produkcyjnego rolnictwa regionu. W szczególności analiza ta pozwoliła na wskazanie regionów wyspecjalizowanych oraz charakteru zmian strukturalnych w zakresie badanego zjawiska. Badania przeprowadzono na podstawie danych dotyczących wielkości produkcji rolnej, w podziale na roślinną i zwierzęcą i ich podgatunki. Wszelkie dane zaczerpnięto z baz danych Głównego Urzędu Statystycznego. Badania obejmują lata 2005-2014.
\end{abstract}

Słowa kluczowe: konkurencyjność, rolnictwo, Esteban-Marquillas

Abstract.The aim of this study is to present the competitiveness of agriculture in the EU countries. The results are based on the Esteban-Marquillas competitiveness model, which allows the diagnosis of a region's production potential. In particular, this analysis allows identification of specialized regions and the nature of structural changes in the examined phenomenon. The study was conducted on the basis of data on the volume of agricultural crop and animal production and their subspecies. All data was taken from the databases of the Central Statistical Office. The study covers the years 2004-2014.

Key words: competitiveness, agriculture, Esteban-Marquillas, European Union

\section{Wprowadzenie}

Konkurencyjność jest szerokim i wielowymiarowym pojęciem definiowanym na różne sposoby z perspektywy firmy, sektora gospodarki i kraju. Jedną z najczęściej przytaczanych definicji jest sformułowana przez Tyson z początków lat 90. Określa ona konkurencyjność jako zdolność do wytwarzania towarów i usług, które są w stanie sprostać międzynarodowej konkurencji, podczas gdy obywatele kraju cieszą się zrównoważonym i rosnącym standardem życia (Tyson, 1992). Możliwość uzyskania lepszych wyników na tle podmiotów konkurencyjnych wpływa na rozwój zarówno przedsiębiorstw, jak i sektorów, regionów czy krajów na konkurencyjnym rynku (Domańska 2013; Domańska, Nowak, 2014). Stankiewicz (2000) proponuje, aby konkurencyjność traktować jako system złożony z czterech podsystemów obejmujących: potencjał konkurencyjności, przewagę konkurencyjną, instrumenty konkurowania oraz pozycję konkurencyjną (Nowak, 2013).

${ }^{1}$ dr, Wydział Ekonomiczny, Uniwersytet Opolski, ul. Ozimska 46a, 45-058 Opole, e-mail: atluczak@uni.opole.pl 
Wieloaspektowość konkurencyjności pozwala na definiowanie jej poprzez zbiór unikalnych zdolności wynikających z zasobów i ich wzajemnych relacji, trudnych do osiągnięcia i naśladowania przez konkurentów (Słodowa-Hełpa, 2003). Konkurencyjność rolnictwa może być rozpatrywana w ramach gospodarki narodowej, wówczas rozpatruje się konkurencyjność wewnętrzną tego działu gospodarki. Z drugiej strony można rozważać konkurencyjność rolnictwa $\mathrm{w}$ ujęciu międzynarodowym, wówczas analizie poddaje się konkurencyjność potencjalną rolnictwa danego kraju (Woś, 2001).

Według definicji OECD konkurencyjność oznacza zarówno zdolność firm, przemysłów, regionów lub narodów do sprostania międzynarodowej konkurencji, co w długim okresie może zwiększać konkurencyjność i prowadzić do wzrostu globalnej produktywności. Szczególnie wzrost produktywności jest istotny dla poprawy konkurencyjności na rynkach otwartych na międzynarodową konkurencję, w celu doprowadzenia do długofalowej poprawy jakości życia oraz kreacji nowych miejsc pracy (Wysokińska, 2002; OECD, 1996). W późniejszej definicji OECD podkreśla się, że konkurencyjność to zdolność do generowania, w wyniku wystawienia na międzynarodową konkurencję, relatywnie wysokich przychodów z czynników produkcji oraz wysokiego zatrudnienia na trwałych podstawach (OECD, 1996a; Wysokińska 2002).

Zdolności konkurencyjne danego regionu uzależnione są od sprawnego funkcjonowania systemu społeczno-gospodarczego na określonym terytorium (państwa, regionu, województwa, itp.). Taki system społeczno-gospodarczy powinien mieć zdolność do rozszerzenia reprodukcji regionalnych i krajowych zasobów, które są wykorzystywane przez dany podmiot gospodarczy - czyli wytwórcę. Konkurencyjność wyraża pozycję i potencjał rozwojowy jednostki, co czyni ją predestynowaną do roli czynnika wyjaśniającego zmiany innych kategorii ekonomicznych. W literaturze przedmiotu wymienianych jest wiele metod pomiaru i badania konkurencyjności regionów. Dotychczas niedocenionym aspektem, w badaniu konkurencyjności, jest osadzenie tej relacji w przestrzeni geograficznej i próba scharakteryzowania jej $\mathrm{z}$ punktu widzenia zachodzących $\mathrm{w}$ tej przestrzeni zmian (Laszkiewicz, 2014).

Celem opracowania jest zbadanie relacji między poziomem konkurencyjności rolnictwa w poszczególnych krajach Unii Europejskiej a przeciętną wielkością produkcji rolnej z 1 ha użytków rolnych. Dodatkowo w pracy podjęto próbę określenia charakteru przestrzennych zmian wielkości produkcji rolnej w podziale na sektory.

\section{Dane i metody}

Punktem wyjścia analizy zmian konkurencyjności w czasie jest klasyczna metoda analizy przesunięć udziałów (shift share analysis), która została opisana po raz pierwszy przez Dunna (1960) oraz Perloffa, Dunna, Lamparda i Mutha (1960). Metoda ta była w kolejnych latach krytykowana, modyfikowana i udoskonalana przez innych autorów, m.in. Houston (1967), Berzeg (1978), Fothergill i Gudgin (1979), Stevens i Moore (1980), Arcelus (1984). Stosowanie $\mathrm{w}$ badaniach rozwoju danego zjawiska społeczno-ekonomicznego analizy SSA polega na dekompozycji całkowitej zmiany zmiennej na trzy części składowe: krajowy, sektorowy, lokalny czynnik wzrostu regionalnego (Trzpiot i in., 2013; Ekonometria przestrzenna, 2010; Tłuczak, 2016). Na mocy zależności pomiędzy pozycją konkurencyjności a efektem zmian strukturalnych, w 1972 roku Esteban-Marquillas zaproponował uwzględnienie $\mathrm{w}$ analizie SSA nowego elementu, tzw. zmiennej 
homotetycznej (Esteban-Marquillas, 1972). Zmodyfikowane przez Estabana-Marquillasa równanie SSA przyjmuje postać:

$$
x_{r i}^{*}-x_{r i}=x_{r i} t x_{. .}+x_{r i}\left(t x_{. i}-t x_{. .}\right)+\hat{x}_{r i}\left(t x_{r i}-t x_{. i}\right)+\left(x_{r i}-\hat{x}_{r i}\right)\left(t x_{r i}-t x_{. i}\right)
$$

gdzie:

$x_{r i}^{*}$ - obserwacje analizowanej zmiennej $\mathrm{X} \mathrm{w}$ r-tym regionie i i-tej grupie podziału przekrojowego w okresie końcowym, $x_{r i}$ - obserwacje analizowanej zmiennej X w r-tym regionie i i-tej grupie podziału przekrojowego w okresie początkowym,

$$
t x_{. .}=\frac{\sum_{r=1}^{R} \sum_{i=1}^{S}\left(x_{r i}^{*}-x_{r i}\right)}{\sum_{r=1}^{R} \sum_{i=1}^{S} x_{r i}} ; \quad t x_{. i}=\frac{\sum_{r=1}^{R}\left(x_{r i}^{*}-x_{r i}\right)}{\sum_{r=1}^{R} x_{r i}} ; \quad t x_{r i}=\frac{x_{r i}^{*}-x_{r i}}{x_{r i}} ; t x_{. .}-\text {krajowy }
$$

(globalny) czynnik wzrostu regionalnego; $t x_{. i}-t x_{. .}-$sektorowy (strukturalny) czynnik wzrostu regionalnego; $t x_{r i}-t x_{. i}-$ lokalny (geograficzny, konkurencyjne, różnicujący) czynnik wzrostu w i-tym sektorze r-tego regionu.

Zamiana wartości $x_{r i} \mathrm{w}$ podstawowym równaniu opisującym SSA wartością $\hat{x}_{r i}$ powoduje oczyszczenie efektu zmian pozycji konkurencyjności z wpływu lokalnych zmian strukturalnych. Pozostała, niewyjaśniona część rzeczywistych zmian zjawiska nazywana jest efektem alokacji:

$$
a_{r i}=\left(x_{r i}-\hat{x}_{r i}\right)\left(t x_{r i}-t x_{. i}\right)
$$

Składnik efektu alokacji ari wskazuje czy r-ty obiekt jest wyspecjalizowany w sensie koncentracji $\mathrm{w}$ tych wariantach zjawiska $\left(x_{r i}-\hat{x}_{r i}\right)$, w których jest najbardziej konkurencyjny $\left(t x_{r i}-t x_{. i}\right)$. Wartość $\hat{x}_{r i}\left(t x_{r i}-t x_{. i}\right)$ jest uważana za wskaźnik przewagi (bądź luki) konkurencyjnej i-tego sektora $\mathrm{w}$ r-tym regionie $\mathrm{w}$ odniesieniu do obszaru referencyjnego. Komponent $\hat{x}_{r i}\left(t x_{r i}-t x_{. i}\right)+\left(x_{r i}-\hat{x}_{r i}\right)\left(t x_{r i}-t x_{. i}\right)$ jest pozytywnie związany z produkcją rolną $\mathrm{w}$ danym sektorze, kiedy dany sektor $\mathrm{w}$ rolnictwie rozwija się szybciej niż cała produkcja rolna oraz region specjalizuje się w danym sektorze (Woźniak, 2010).

Dopuszcza się brak występowania specjalizacji regionu w roku wyjściowym $\left(x_{r i}-\hat{x}_{r i}<0\right)$, a następnie wystąpienie tej specjalizacji $\mathrm{w}$ roku końcowym analizy $\left(x_{r i}^{*}-\hat{x}_{r i}^{*}>0\right)$.

Efekt alokacji przyjmie wartości dodatnie $\mathrm{w}$ tych regionach, które specjalizują się w sektorach, w których tempo wzrostu jest większe niż wynosi globalny wzrost regionalny, i odwrotnie, jeśli tempo wzrostu w regionach jest niższe niż globalne, wówczas efekt alokacji przyjmuje wartości ujemne, a o regionie można mówić, że nie występuje w nim specjalizacja 
badanego zjawiska w zadanym sektorze. Im większa wartość efektu alokacji dla całego regionu tym lepiej badane zjawisko rozkłada się pomiędzy analizowane sektory. Jeśli w danym regionie nie występuje specjalizacja wówczas efekt alokacji przyjmuje wartość zero, a region nie korzysta z przewag konkurencyjnych.

Tabela 1. Charakterystyka efektu alokacji

Table 1. Characterization of the allocation effect

\begin{tabular}{|c|c|c|c|}
\hline \multirow[b]{2}{*}{ Wyszczególnienie } & \multirow[b]{2}{*}{ Znak ari } & \multicolumn{2}{|c|}{ Znak składników ari } \\
\hline & & $\begin{array}{l}\text { Specjalizacja } \\
\left(x_{r i}-\hat{x}_{r i}\right)\end{array}$ & $\begin{array}{c}\text { konkurencyjność } \\
\left(t x_{r i}-t x_{. i}\right)\end{array}$ \\
\hline $\begin{array}{l}\text { Wyspecjalizowanie obiektu, } \\
\text { niekorzyśc konkurencyjności }\end{array}$ & - & + & - \\
\hline $\begin{array}{l}\text { Brak specjalizacji obiektu, } \\
\text { niekorzyść konkurencyjności }\end{array}$ & + & - & - \\
\hline $\begin{array}{l}\text { Brak specjalizacji obiektu, korzyść } \\
\text { konkurencyjności }\end{array}$ & - & - & + \\
\hline $\begin{array}{l}\text { Wyspecjalizowanie obiektu, korzyść } \\
\text { konkurencyjności }\end{array}$ & + & + & + \\
\hline
\end{tabular}

Źródło: Ekonometria przestrzenna. Metody i modele analizy danych przestrzennych (2010), red. B. Suchecki, C.H. Beck, Warszawa, s. 184.

\section{Wyniki badań}

Analiza struktury produkcji rolnej została wykonana dla krajów członkowskich Unii Europejskiej ${ }^{2} \mathrm{w}$ odniesieniu do poziomu rozwoju tego zjawiska w całej UE. Dane do badania zaczerpnięto z baz danych Głównego Urzędu Statystycznego ${ }^{3}$. Zawierały wielkość produkcji rolnej w poszczególnych krajach $(\mathrm{r}=1, \ldots, 26)$ oraz podział strukturalny produkcji rolnej na zwierzęcą według rodzaju $(\mathrm{i}=1,2,3$; żywiec wołowy, wieprzowy, mleko) oraz roślinną według gatunku zbóż (i=1,2,3; pszenica, żyto, jęczmień). Zakres czasowy badania obejmował lata 2005-2014, przy czym dla porównania i identyfikacji zmian w okresie tym wyodrębniono dwa podokresy 2005-2010, 2010-20144.

W tabeli 2 przedstawiono kraje, w których w sektorze produkcji zwierzęcej efekt alokacji przyjmował wartości dodatnie.

Kraje dla których oba komponenty efektu alokacji były dodatnie, charakteryzują się wyspecjalizowaniem $\mathrm{w}$ zakresie produkcji zwierzęcej i jednocześnie przewagą konkurencyjną w stosunku do pozostałych krajów w zakresie produkcji poszczególnych gatunków żywca oraz mleka. Pozostałe kraje (nie wymienione w tabeli 1) charakteryzują ujemne wartości efektu alokacji. Na uwagę zasługują Węgry oraz Bułgaria, w przypadku których dla dodatnich wartości komponentu specjalizacji występują jednocześnie ujemne wartości komponentu konkurencyjności. To oznacza, że w krajach tych występuje luka konkurencyjna $\mathrm{w}$ analizowanych sektorach produkcji zwierzęcej.

\footnotetext{
${ }^{2}$ Ze względu na brak kompletności danych w rozważaniach pominięto Maltę, Luksemburg oraz Cypr.

${ }^{3}$ Rocznik Statystyczny Rolnictwa 2016, Warszawa, GUS.

${ }^{4}$ Podokresy wynikały z dostępności danych.
} 
Tabela 2. Efekt alokacji dla produkcji zwierzęcej w krajach UE w latach 2005-2014

Table 2. Allocation effect for animal production in UE countries in 2005-2014

\begin{tabular}{|c|c|c|c|c|}
\hline \multicolumn{5}{|c|}{$2005-2010$} \\
\hline Specjalizacja & Konkurencyjność & Bydło & trzoda & mleko \\
\hline- & - & $\begin{array}{l}\text { Belgia, Bułgaria, } \\
\text { Chorwacja, } \\
\text { Holandia, Łotwa, } \\
\text { Portugalia, } \\
\text { Słowacja, Węgry }\end{array}$ & $\begin{array}{c}\text { Bułgaria, Estonia, } \\
\text { Francja, Litwa, } \\
\text { Łotwa }\end{array}$ & Francja, Rumunia, Włochy \\
\hline+ & + & $\begin{array}{l}\text { Finlandia, Francja, } \\
\text { Grecja, Litwa, } \\
\text { Polska, Rumunia, } \\
\text { Szwecja, Wielka } \\
\text { Brytania, Włochy }\end{array}$ & $\begin{array}{l}\text { Holandia, } \\
\text { Irlandia, } \\
\text { Rumunia, } \\
\text { Szwecja, Węgry, } \\
\text { Włochy }\end{array}$ & $\begin{array}{c}\text { Austria, Belgia, Bułgaria, } \\
\text { Chorwacja, Czechy, Dania, } \\
\text { Estonia, Hiszpania, Holandia, } \\
\text { Irlandia, Litwa, Łotwa, Niemcy, } \\
\text { Portugalia, Słowacja, Słowenia }\end{array}$ \\
\hline \multicolumn{5}{|c|}{ 2010-2014 } \\
\hline- & - & $\begin{array}{l}\text { Belgia, Dania, } \\
\text { Finlandia, } \\
\text { Rumunia, } \\
\text { Słowacja, Wielka } \\
\text { Brytania, Włochy }\end{array}$ & $\begin{array}{l}\text { Bułgaria, } \\
\text { Chorwacja, } \\
\text { Francja, } \\
\text { Hiszpania, } \\
\text { Rumunia, } \\
\text { Słowenia }\end{array}$ & Chorwacja,Irlandia \\
\hline+ & + & $\begin{array}{l}\text { Chorwacja, } \\
\text { Irlandia, Polska }\end{array}$ & $\begin{array}{l}\text { Irlandia, Polska, } \\
\text { Portugalia, }\end{array}$ & $\begin{array}{c}\text { Austria, Belgia, Czechy, Dania, } \\
\text { Estonia, Finlandia, Francja, Grecja, } \\
\text { Hiszpania, Holandia, Litwa, } \\
\text { Łotwa, Niemcy, Rumunia, } \\
\text { Słowacja, Słowenia, Szwecja, } \\
\text { Węgry, Wielka Brytania, Włochy }\end{array}$ \\
\hline
\end{tabular}

Źródło: opracowanie na podstawie badań własnych.

W latach 2005-2010 odnotowano duże zróżnicowanie wartości efektu alokacji we wszystkich analizowanych dwóch sektorach produkcji roślinnej. W przypadku pszenicy tylko siedem krajów: Austria, Belgia, Bułgaria, Czechy, Estonia, Irlandia, Łotwa, Portugalia, Słowacja, Słowenia oraz Szwecja charakteryzują się ujemną wartością efektu alokacji. W przypadku produkcji roślinnej (zbóż) liczba państw dla których efekt alokacji przyjmuje wartości ujemne jest znacznie większa niż krajów z dodatnim efektem alokacji w latach 2010-2014. Oznacza to, ze tempo wzrostu produkcji roślinnej w tych krajach jest niższe niż globalne, dodatkowo w krajach tych nie występuje specjalizacja badanego zjawiska w zadanym sektorze (produkcji roślinnej). Na zaistniałą sytuację z pewnością wpływ miały niesprzyjające warunki pogodowe (susze, powodzie), które przełożyły się na niższe zbiory.

W strukturze produkcji w analizowanych podokresach w wybranych krajach zaszły korzystne zmiany, polegające na korzystnej restrukturyzacji produkcji rolnej, spójnej z lokalną korzyścią lub niekorzyścią związaną z konkurencyjnością. Wspomniane zmiany dotyczą Belgii i Węgier - sektor pszenicy, Bułgarii, Grecji, Hiszpanii, Słowenii - sektor żyta oraz Czech, Grecji, Holandii, Litwy, Niemiec, Rumunii - sektor jęczmienia. W krajach tych dokonała się restrukturyzacja produkcji rolnej, która miała pozytywny wpływ na całokształt rolnictwa. W sektorze zwierzęcej produkcji rolnej oraz produkcji mleka pozytywna zmiana zaszła w niewielu krajach. Do tej grupy należą: Irlandia i Czechy - bydło; Chorwacja, Hiszpania, Polska, Portugalia, Słowenia - trzoda; Finlandia, Grecja, Szwecja, Węgry i Wielka Brytania - mleko. 
Tabela 3. Efekt alokacji dla produkcji roślinnej w krajach UE w latach 2005-2014

Table 3. Allocation effect for crop production in UE countries in 2005-2014

\begin{tabular}{|c|c|c|c|c|}
\hline \multicolumn{5}{|c|}{$2005-2010$} \\
\hline Specjalizacja & Konkurencyjność & Pszenica & żyto & Jęczmień \\
\hline- & - & $\begin{array}{l}\text { Chorwacja, Dania, } \\
\text { Finlandia, Francja, } \\
\text { Łotwa, Portugalia, } \\
\text { Słowenia, Szwecja }\end{array}$ & $\begin{array}{c}\text { Austria, Belgia, } \\
\text { Chorwacja, Czechy, } \\
\text { Estonia, Litwa, Łotwa, } \\
\text { Szwecja, Węgry }\end{array}$ & $\begin{array}{l}\text { Finlandia, Rumunia, } \\
\text { Wielka Brytania }\end{array}$ \\
\hline+ & + & $\begin{array}{c}\text { Grecja, Hiszpania, } \\
\text { Holandia, Niemcy, } \\
\text { Polska, Wielka } \\
\text { Brytania, Włochy }\end{array}$ & $\begin{array}{c}\text { Dania, Finlandia, } \\
\text { Francja, Hiszpania, } \\
\text { Holandia, Niemcy, } \\
\text { Portugalia, Słowacja, } \\
\text { Wielka Brytania, } \\
\text { Włochy }\end{array}$ & $\begin{array}{l}\text { Austria, Belgia, } \\
\text { Bułgaria, Chorwacja, } \\
\text { Hiszpania, Irlandia, } \\
\text { Łotwa, Polska, } \\
\text { Portugalia, Słowacja }\end{array}$ \\
\hline \multicolumn{5}{|c|}{ 2010-2014 } \\
\hline- & - & Grecja, Włochy & $\begin{array}{c}\text { Chorwacja, Francja, } \\
\text { Grecja, Hiszpania, } \\
\text { Holandia, Wielka } \\
\text { Brytania }\end{array}$ & \\
\hline+ & + & $\begin{array}{c}\text { Belgia, Chorwacja, } \\
\text { Finlandia, Francja, } \\
\text { Portugalia, Węgry, } \\
\text { Wielka Brytania }\end{array}$ & $\begin{array}{c}\text { Austria, Belgia, } \\
\text { Bułgaria, Dania, } \\
\text { Estonia, Irlandia, } \\
\text { Łotwa, Niemcy, } \\
\text { Słowacja, Słowenia, } \\
\text { Szwecja }\end{array}$ & $\begin{array}{c}\text { Austria, Chorwacja, } \\
\text { Czechy, Grecja, } \\
\text { Holandia, Litwa, } \\
\text { Niemcy, Polska, } \\
\text { Portugalia, Rumunia, } \\
\text { Szwecja, Węgry, Wielka } \\
\text { Brytania, Włochy }\end{array}$ \\
\hline
\end{tabular}

Źródło: opracowanie na podstawie badań własnych.

\section{PODSUMOWANIE}

W opracowaniu skoncentrowano się na wybranym aspekcie zmian struktury produkcji rolnej. Właściwy kierunek produkcji rolnej przy zastanym potencjale regionu może przynieść producentom rolnym wysokie dochody. Zmiana kierunku produkcji częstokroć kosztowna może uchronić od poniesienia dodatkowych kosztów. Podjęta analiza produkcji zwierzęcej ma charakter niewyczerpujący. Każdy analizowany region ma swoje specyficzne cechy, które mają wpływ na tempo i kierunki jego rozwoju gospodarczego i społecznego. Bazując na metodzie Estebana-Marquillasa można:

1. zidentyfikować przewagi (luki) konkurencyjne krajów;

2. dokonać oceny stopnia specjalizacji krajów w danym sektorze produkcji rolnej;

3. dokonać oceny wpływu na dany sektor kondycji całego rolnictwa;

4. dokonać oceny wpływu zmian $w$ danym sektorze na całe rolnictwo.

$\mathrm{Na}$ wyniki badań z pewnością wpływ miał dobór analizowanych lat oraz podział głównego okresu na podokresy. Przedstawioną analizę należałoby rozszerzyć o inne sektory produkcji rolnej, które zyskują coraz większe znaczenie. W zależności od badanego okresu zmienia się stopień specjalizacji krajów $\mathrm{w}$ danym sektorze oraz zmienia się pozycja konkurencyjna. Patrząc długookresowo, najlepiej sytuacja przedstawia się w przypadku mleka, ponieważ w tym sektorze efekt alokacji oraz jego składowe (komponent specjalizacji 
i komponent konkurencyjności) były dodatnie. Sytuacja w przypadku sektora pszenicy wydaje się najbardziej zróżnicowana. Jest jednak grupa krajów, które nie niwelują swych luk konkurencyjnych w rozważanym sektorze produkcji rolnej.

\section{BIBLIOGRAFIA}

Arcelus, F.J. (1984). An Extension of Shift-Share Analysis. Growth and Change, 15, 3-8.

Berzeg, K. (1978). The empirical content of shift-share analysis. Journal of Regional Science, 18, 463-468.

Domańska, K. (2013). Konkurencyjność produkcji mleka w Polsce w ujęciu regionalnym, Roczniki Naukowe SERiA, 15(4), 105-111

Domańska, K., Nowak, A. (2014). Konkurencyjność polskiego rolnictwa na rynku Unii Europejskiej. Prace Naukowe Uniwersytetu Ekonomicznego we Wrocławiu, (361), 29-37.

Dunn, E.S. (1960). A Statistical and Analytical Technique for Regional Analysis. Papers and Proceedings of the Regional Science Association, 6, 98-112.

Ekonometria przestrzenna. Metody i modele analizy danych przestrzennych (2010) red. B. Suchecki, C. H. Beck, Warszawa, 162-194.

Esteban-Marquillas, J.M. (1972). Shift and Share analysis revisited. Regional and Urban Economics, 2(3), $249-261$.

Fothergill, S., Gudgin, G. (1967). In defence of shift-share. Urban Studies, 16, 309-319.

Houston, D.B. (1967). The Shift and Share Analysis of Regional Growth: A Critique. Southern Economic Journal, 33(4), 577-581.

Łaszkiewicz, E. (2014). Wpływ konkurencyjności na poziom wynagrodzeń w krajach Europy. Analiza z wykorzystaniem modelu trendu powierzchniowego. Acta Universitatis Nicolai Copernici Ekonomia, 45(1), 41-58.

Nowak, A. (2013). Produktywność rolnictwa polskiego w kontekście jego konkurencyjności. Folia Pomeranae Universitatis Technologiae Stetinensis. Oeconomica, 70, 159-168.

OECD (1996). Industrial Structure Statistics 1994, Paris 1996, 17-19.

OECD (1996a). Globalisation and Competitiveness: Relevant Indicators, „STI Working Papers”, no 16/1996, Paris

Perloff, H.S., Dunn, E.S., Lampard, E.E., Muth, R.F. (1960). Regions, resources and economic growth, Johns Hopkins Press, Baltimore

Słodowa-Hełpa, M. (2003). Konkurencyjność-główne wyzwanie dla polskich wspólnot lokalnych i regionalnych w zintegrowanej Europie. Zeszyty Naukowe Wyższej Szkoły Bankowej w Poznaniu, (16), 111-129.

Stankiewicz, M.J. (2000). Istota i sposoby oceny konkurencyjności przedsiębiorstwa. Gospodarka Narodowa, (7-8), 95-111.

Stevens, B., Moore, C.L. (1980). A critical review of the literature on shift-share as a forecasting technique. Journal of Regional Science, 20, 419-437.

Tluczak, A. (2016). Metoda zmian konkurencyjności Estebana - Marquillasa a specjalizacja regionu na przykładzie produkcji zwierzęcej w Polsce. Metody Ilościowe w Badaniach Ekonomicznych, 17(3), 152-160.

Trzpiot, G., Ojrzyńska, A., Szołtysek, J., Twaróg, S. (2013). Wykorzystanie shift share analysis w opisie zmian struktury honorowych dawców krwi w Polsce. Wielowymiarowe modelowanie i analiza ryzyka, UE Katowice, Katowice, 84-98.

Tyson, L., (1992). Who's bashing whom: trade conflict in high technology industries, Institute for International Economics, Washington D.C.

Woś, A. (2001). Konkurencyjność wewnętrzna rolnictwa. Warszawa, IERiGŻ, 30-34.

Woźniak, D. (2010). Identyfikacja przewag konkurencyjnych regionu. W: Organizacje komercyjne i niekomercyjne wobec wzmożonej konkurencji oraz wzrastających wymagań konsumentów, red. A. Nalepka, A Ujwara-Gil, Sowa Drukarnia Cyfrowa, Warszawa, 235-240.

Wysokińska, Z. (2002). Konkurencyjność w międzynarodowym i globalnym handlu towarami technologicznie intensywnymi (high-tech). Studia Europejskie, 1, 127-159. 